\title{
New Treatment for Driveline Infection Following Implantation of a Ventricular Assist Device
}

\author{
Akira Sezai, MD, PhD, Satoshi Unosawa, MD, PhD, Makoto Taoka, MD, PhD, Shunji Osaka, MD, PhD, \\ Yoshiki Kitazumi, MD, Keito Suzuki, MD, Toshiko Nakai, MD, PhD, and Masashi Tanaka, MD, PhD \\ The Department of Cardiovascular Surgery, the Department of Cardiology, Nihon University School of Medicine, Tokyo, Japan
}

\section{ABSTRACT}

In patients with an implantable ventricular assist device (VAD), driveline infection (DLI) is a challenging complication. Once DLI occurs, it may lead to pump contamination and/or septicemia, which means that early treatment is essential. We hereby report our initial experiences of a mechanically-powered portable negative pressure wound therapy system (Smart Negative Pressure: $\mathrm{SNaP}^{\mathrm{TM}}$ ) to treat DLI at an outpatient clinic.

\section{INTRODUCTION}

Driveline infection (DLI) is one of the important complications in patients with an implantable ventricular assist device (VAD), since it can lead to pump infection and/or septicemia [Imamura 2017; Kimura 2014].

A patient at our hospital with an extracorporeal VAD developed cannula site infection, due to methicillin-resistant Staphylococcus aureus (MRSA), which we treated by the Nihon University crystal violet method, resulting in elimination of MRSA and improvement of the cannula site infection [Sezai 2016]. Based on that experience, this method has been adopted at our hospital for prevention of DLI in patients with an implantable VAD [Sezai 2016]. This time, we encountered a patient with an implantable VAD who developed DLI, and we achieved a good outcome by providing negative pressure wound therapy (NPWT) on an outpatient basis.

\section{CASE REPORT}

A 66-year-old man with dilated cardiomyopathy had undergone implantation of a VAD (HeartMate II, Abott, IL, USA) 2 years previously without complications. In order to prevent DLI, the triple tunnel method was used (ie, the DL was placed in the subfascial layer of the rectus muscle with a silicone interface at the exit site) [Yoshitake 2018], and the

Received fuly 17, 2019; accepted October 1, 2019.

Correspondence: Akira Sezai, MD, PhD, The Department of Cardiovascular Surgery, Nihon University School of Medicine, 30-1, Oyaguchi-kamimachi, Itabashi-ku, Tokyo 173-8610, Japan; fax: +81-3-3955-9818; +81-3-39728111 (e-mail: asezai.med@gmail.com). skin around the driveline exit site was managed by the Nihon University crystal violet method [Sezai 2016; Sezai 2016]. However, DLI due to methicillin-sensitive Staphylococcus aureus (MSSA) occurred at 1 year following implantation because of inappropriate treatment after showering. A $2 \mathrm{~cm}$ incision was made around the driveline and debridement was performed, followed by treatment with the Nihon University crystal violet method. The infection improved, and the patient was discharged. Amiodarone-induced interstitial pneumonia occurred 5 months after discharge and MRSA was detected in the sputum. Treatment of interstitial pneumonia was difficult and required ventilation, steroid pulse therapy, and administration of vancomycin. Although the patient's interstitial pneumonia improved, DLI progressed during treatment. (Figure 1A) An incision of about $3 \mathrm{~cm}$ was made around the driveline to allow debridement, and NPWT was conducted for 3 months using the ActiVAC system (KCI, Inc., Tokyo, Japan). MSSA was detected in the wound. Since the wound decreased in size (Figures 1B, 1C), use of the ActiVAC system was discontinued, and it was switched to a mechanicallypowered, ultraportable NPWT system (Smart Negative Pressure: SNaP ${ }^{\mathrm{TM}}$, KCI, Inc., Tokyo, Japan). (Figure 2A) The $\mathrm{SNaP}^{\mathrm{TM}}$ system is used as follows: 1) Tegaderm ${ }^{\mathrm{TM}}$ is applied to the skin to prevent aspiration-induced injury; 2) Blue foam material is placed in the wound (Figure 2B); 3) A $2 \times 3$ $\mathrm{cm}$ piece of foam material is placed on top of the material

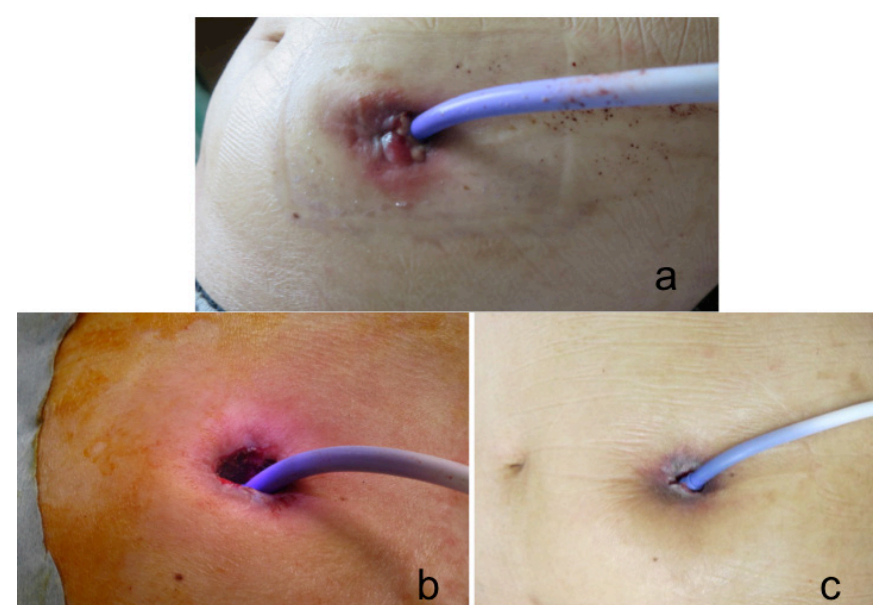

Figure 1. A, Driveline infection. B, Before treatment of DLI with the $\mathrm{SNaP}{ }^{\mathrm{TM}}$ system. C, After 8 months of treatment with the $\mathrm{SNaP}{ }^{\mathrm{TM}}$ system. 


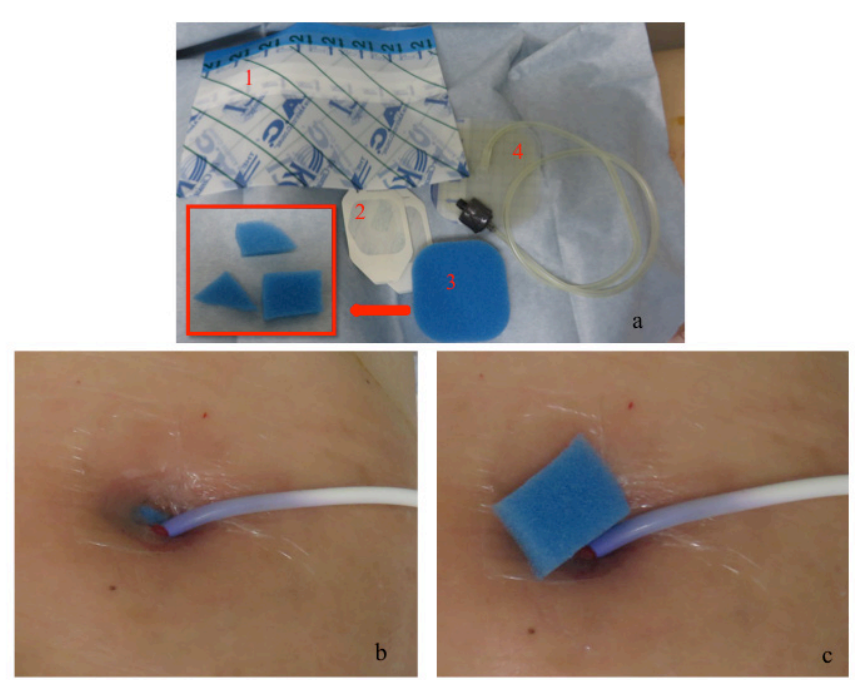

Figure 2. A, The SNaPTM system. 1. Polyurethane tape, 2. Tegaderm ${ }^{\mathrm{TM}}$, 3. foam material, 4. Hydrocolloid dressing with an aspiration tube. B, Blue foam material is placed in the wound. C, A $2 \times 3 \mathrm{~cm}$ piece of foam material is placed on top of the material packed into the wound.

packed into the wound (Figure 2C); 4) Hydrocolloid dressing with an aspiration tube is placed so that the tube is in contact with the foam material (Figure 3A); 5) Polyurethane tape is applied to cover the driveline (Figure 3B); 6) Polyurethane tape is applied to the edges of the dressing and is connected to the cartridge (Figure $3 \mathrm{C}$ ). There has been no exacerbation of DLI since the patient was discharged 8 months ago. The $\mathrm{SNaP}^{\mathrm{TM}}$ system is replaced once or twice per week, while the patient is waiting for heart transplantation.

\section{DISCUSSION}

The device infection rate at 3 years after VAD implantation is reported to be approximately $30 \%$, with DLI being the main type of infection. Several strategies have been explored to prevent DLI, including 1) fixation to reduce skin tension at the DL exit site, 2) meticulous exit site care, and 3) different DL locations. However, there currently is no standard regimen [Kirklin 2015; Cook 2017]. If DLI occurs, early intervention is needed to ensure drainage of pus and control the infection. When the velour interface of DL becomes contaminated, radical debridement, exit site relocation, and advancement of a local tissue flap may be needed. If DLI does not rapidly improve, NPWT commonly is performed with the ActiVAC system. In our patient with mild DLI, use of the $\mathrm{SNaP}^{\mathrm{TM}}$ system allowed management on an outpatient basis. Based on our experience, treatment with the $\mathrm{SNaP}^{\mathrm{TM}}$ system is possible if the infected wound is within $3 \mathrm{~cm}$ of the driveline and is $=<5 \mathrm{~cm}$ in depth.

NPWT using the $\mathrm{SNaP}^{\mathrm{TM}}$ system already has been reported for lower extremity ulcer and trauma [Fong 2012; Armstrong 2012], but this is the first application to DLI as far as we could determine. A study that compared conventional NPWT with the $\mathrm{SNaP}^{\mathrm{TM}}$ system for lower extremity ulcers

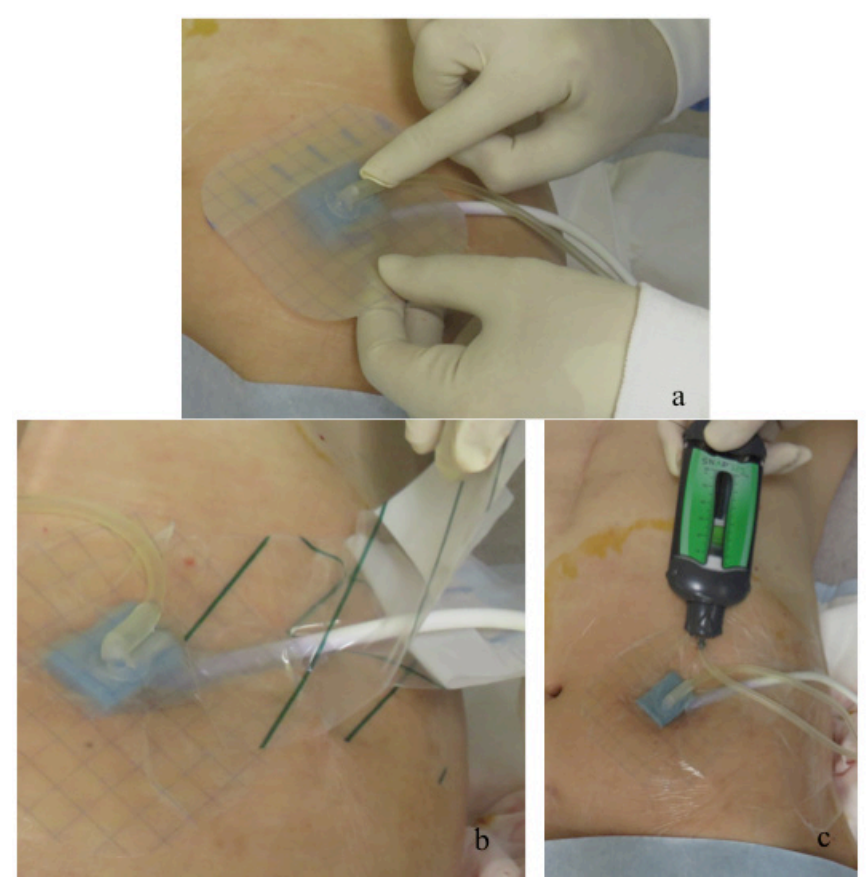

Figure 3. A, Hydrocolloid dressing with an aspiration tube is placed so that the tube is in contact with the foam material. B, Polyurethane tape is applied to cover the driveline. C, Polyurethane tape is applied to the edges of the dressing and is connected to the cartridge.

found no difference of the lesion shrinkage rate [Armstrong 2012]. In Japan, NPWT with the ActiVAC system is only covered by health insurance when a patient is hospitalized and not when it is performed at an outpatient clinic, while the $\mathrm{SNaP}^{\mathrm{TM}}$ system is the only NPWT method approved for outpatient use. The $\mathrm{SNaP}^{\mathrm{TM}}$ system is non-electrical and suction with up to $125 \mathrm{mmHg}$ of negative pressure is achieved by using a constant load spring. There are 2 cartridge sizes (60 $\mathrm{mL}$ and $150 \mathrm{~mL}$ ). Since the $\mathrm{SNaP}^{\mathrm{TM}}$ system is small and light, patients can perform daily activities while using it and can be treated at an outpatient clinic.

In conclusion, when DLI occurs in a patient waiting for heart transplantation or destination therapy, it is important to perform early incision and NPW'T before the infection becomes deep-seated. We used the $\mathrm{SNaP}^{\mathrm{TM}}$ system to treat DLI. Although we cannot conclude because we have only experienced one case, management methods of DLI with this system seems to be useful for improving the quality of life in patients with mild infection.

\section{REFERENCES}

Armstrong DG, Marston WA, Reyzelman AM, Kirsner RS. 2012. Comparative effectiveness of mechanically and electrically powered negative pressure wound therapy devices: A multicenter randomized-controlled trial, Wound Repair Regen 20:332-41.

Cook JL, Colvin M, Francis GS, Grady KL, Hoffman TM, Jessup M, John R, Kiernan MS, Mitchell JE, Pagani FD, Petty M, Ravichandran 
P, Rogers JG, Semigran MJ, Toole JM. 2017. Recommendations for the Use of Mechanical Circulatory Support: Ambulatory and Community Patient Care: A Scientific Statement From the American Heart Association. Circulation 135:e1145-58.

Fong KD, Marston WA. 2012. SNaP® wound care system: ultraportable mechanically powered negative pressure wound therapy. Adv Wound Care (New Rochelle) 1:41-3.

Imamura T, Murasawa T, Kawasaki H, Kashiwa K, Kinoshita O, Nawata K, Ono M. 2017. Correlation between driveline features and driveline infection in left ventricular assist device selection. J Artif Organs 20:34-41.

Kimura M, Nishimura T, Kinoshita O, Okada S, Inafuku H, Kyo S, Ono M. 2014. Successful treatment of pump pocket infection after left ventricular assist device implantation by negative pressure wound therapy and omental transposition. Ann Thorac Cardiovasc Surg 20 Suppl:842-5.
Kirklin JK, Naftel DC, Pagani FD, Kormos RL, Stevenson LW, Blume ED, Myers SL, Miller MA, Baldwin JT, Young JB. 2015. Seventh INTERMACS annual report: 15,000 patients and counting. J Heart Lung Transplant. 34:1495-504.

Sezai A, Niino T, Osaka S, Yaoita H, Arimoto M, Hata H, Shiono M. 2016. New treatment for infection of the NIPRO LVAD cannula site: Nihon University crystal violet method. Ann Thorac Surg 101:348-50.

Sezai A, Niino T, Osaka S, Yaoita H, Arimoto M, Hata H, Shiono M. 2016. New treatment for percutaneous sites in patients with a ventricular assist device: Nihon University crystal violet method. Ann Thorac Cardiovasc Surg 22:246-50.

Yoshitake S, Kinoshita O, Nawata K, Hoshino Y, Itoda Y, Kimura M, Yamauchi H, Ono M. 2018. Novel driveline route for prevention from driveline infection: Triple tunnel method. J Cardiol 72:363-6. 